\title{
O jogo de regras Rummikub e as possibilidades de negociação interpares
}

\author{
Gisele Bueno de Farias Rebeiro \\ Francismara Neves Oliveira \\ Geiva Carolina Calsa
}

\section{Resumo}

No aporte teórico de Jean Piaget, a negociação da perspectiva é considerada processo que vai do egocentrismo à reciprocidade. O artigo objetivou analisar as condutas no jogo Rummikub e a negociação da perspectiva interpares. A pesquisa qualitativa na modalidade de estudo descritivo ocorreu em uma escola estadual em Londrina - PR e dela participaram 8 alunos da sala de apoio. Foram realizadas 10 sessões com o jogo - 4 de aprendizagem e 6 avaliativas. Os resultados demonstraram que as jogadas predominantemente egocêntricas e autocentradas estão relacionadas à dificuldade de antecipação, autocontrole e ausência de autonomia na aprendizagem. As condutas mais recíprocas relacionaramse à autonomia, planejamento de ações e enfrentamento dos desafios. Condutas mais egocêntricas no jogo corresponderam à maior necessidade de trapacear, usar estratégias contrárias às regras e autofavorecedoras. A negociação das perspectivas deve ser oportunizada em situações de aprendizagem escolar nas quais os aspectos sociais, afetivos e cognitivos encontram-se interdependentes.

Palavras-chave: Negociação de perspectivas, Jean Piaget, jogo de regras.

\section{Rummikub game rules and the possibilities of interlayer negotiations}

\begin{abstract}
According to Jean Piaget's theory, negotiation of perspective is considered a process that goes from egocentrism to reciprocity. In this article we aim at analyzing the conducts at Rummikub game and the peer's negotiation of perspective. We conducted this qualitative research in the modality of a descriptive study in a state school in Londrina-PR with 8 students of a supportive classroom. We had ten sessions on the game - four dedicated to learning and six to evaluation. The results demonstrated that the egocentric and individual-centered plays are related to the difficulty in anticipation and self-control and of the absence of learning autonomy. The plays with more reciprocal conducts were related to autonomy, to the planning of actions and to a higher disposition to face challenges. More egocentric conducts in the game corresponded to a higher need to cheat or use strategies contrary to the rules and self-beneficial. We argue that negotiation of perspectives must be favored in learning situations in schools among peers, for they allow an exchange to take place in which the social, emotional and cognitive aspects are found to be interdependent.
\end{abstract}

Key-words: Perspective negotiations, Jean Piaget, game of rules.

\section{El juego de reglas Rummikub y las posibilidades de negociación inter pares}

\section{Resumen}

El aporte teórico de Jean Piaget señala que la negociación de la perspectiva es considerada proceso que transita del egocentrismo a la reciprocidad. El artículo tuvo el objetivo de analizar las conductas en juego Rummikub y la negociación de la perspectiva inter pares. La investigación cualitativa en la modalidad de estudio descriptivo sucedió en una escuela estatal en Londrina (Paraná) y contó con la participación de 8 alumnos de la sala de apoyo. Se realizaron 10 sesiones con el juego - 4 de aprendizaje y 6 evaluativas. Los resultados demostraron que las jugadas predominantemente egocéntricas y auto-centradas están relacionadas a la dificultad de anticipación, autocontrol y ausencia de autonomía en el aprendizaje. Las conductas más recíprocas se relacionaron a la autonomía, planificación de acciones y enfrentamiento de desafíos. Conductas más egocéntricas en el juego correspondieron a mayor necesidad de hacer trampas, usar estrategias que burlan reglas y que se muestran auto-favorecedoras. La negociación de perspectivas debe ser posibilitada en situaciones de aprendizaje escolar en las que los aspectos sociales, afectivos y cognitivos son interdependientes.

Palabras Clave: Negociación de perspectivas, Jean Piaget, juego de reglas. 


\section{Introdução}

O artigo objetivou analisar, por meio das condutas lúdicas de jogadores do jogo Rummikub, o egocentrismo e a reciprocidade como constituintes da tomada da perspectiva do outro, na relação interpares. A problemática estudada foi ancorada na epistemologia genética, que propõe o estudo da "significação dos conhecimentos, das estruturas operatórias ou de noções, recorrendo à sua história e ao seu funcionamento atual em uma ciência determinada" (Piaget, 1965/1969, p.77). O referencial eleito permitiu reflexões acerca do jogo de regras como possibilidade de observação das construções internas do sujeito e das interações entre pares, por meio dos procedimentos empregados pelos jogadores.

Como problemática do estudo questionou-se como se manifestava, no contexto de um jogo de regras, a negociação da perspectiva do outro, favorecida na interação social. A interação social é considerada, na teoria, fator importante à construção cognitiva e por isso é compreendida como uma necessidade do processo de constituição da lógica, uma vez que o sujeito é convidado constantemente à resolução de conflitos impostos nas interações com os objetos de conhecimento, com o outro e consigo mesmo (Garcia, 2010; Macedo, 1994, 2009; Oliveira, 2005; Tortella, 2001; Turiel \& Smetana, 1989).

Da ação prática irreversível à coordenação das ações interiorizadas, há um processo de construção sociocognitiva acontecendo gradativamente. $\mathrm{Na}$ teoria de Piaget uma estrutura sempre se constitui por aquilo que a antecede e contempla as possibilidades em construção a serem solidificadas a posteriori. Implicada nessa compreensão está à ideia de processos interdependentes ocorrendo com elementos solidários.

No caso do nosso estudo, a construção dos sujeitos engloba aspectos sociais, afetivos e cognitivos em interação, solidários e interligados, presentes nos procedimentos dos jogadores. Esse processo é gradativo e espiralado em sua evolução. Na teoria adotada como aporte e em especial nas clássicas obras $O$ nascimento da inteligência na criança (1982), A psicologia da criança (1980) e A formação do símbolo na criança (1946/1978), Piaget deixa explicitada sua preocupação em descrever um processo de construção da inteligência. Aponta minuciosamente a passagem do conhecimento prático, sensório-motor ao plano representacional e às operações mentais. Deixa marcada a compreensão de que as ações constituem de modo "embrionário" as operações da inteligência, em processo.

A operação caracteriza-se pela interiorização de uma ação reversível, coordenada, integrada às estruturas operatórias de conjunto (Piaget, 1982). Porém, para que uma ação se torne uma operação, ela não prescinde da função simbólica que permite a diferenciação dos significantes (signos e símbolos) e dos significados (objetos e acontecimentos). Assim sendo, o progresso lógico é codependente da socialização do pensamento, pois a interação social apresenta aos participantes situações que requerem coordenações de suas próprias ações ou confrontação de seus pontos de vis- ta, o que pode desencadear modificações na estruturação cognitiva individual.

Assegurada na compreensão desses princípios, a problemática de nosso estudo buscou investigar possibilidades de negociação da própria perspectiva na interação com o outro por meio de situações vividas no contexto de um jogo de regras que, na perspectiva teórica piagetiana, é explorado como espaço de construção cognitiva e afetivo-social (Brenelli, 1996; Oliveira, 2005). Os estudiosos do jogo, apoiados em Piaget, consideram-no rico por engendrar possibilidades de conflito cognitivo, interação interpares, significação e compreensão (Fiorot \& Ortega, 2009; Macedo, 2009; Ribeiro \& Rossetti, 2009). No presente estudo com o jogo de regras Rummikub, interessou-nos verificar se e como os jogadores descentravam sua própria perspectiva e adotavam a de outros jogadores diante de conflitos cognitivos (pensamento e elaboração de estratégias advindos da insuficiência da estrutura de pensamento e das contradições entre o pensamento e as exigências do jogo) e conflitos sociais (contestação ou contradição do seu desejo pelo parceiro, pela jogada realizada pelo outro, emoções envolvidas).

Os conflitos cognitivos e sociais são possibilidades de crescimento por meio da interação; criam contestações, geram perturbações, engendram problemas a serem solucionados (Oliveira \& Macedo, 2011). Eles acontecem nas interações sociais a partir do momento em que os envolvidos agem e debatem sobre determinada situação-problema, oportunizando diferentes percepções do real.

Coordenar suas ações com as do outro, compreender as ações sobre o tabuleiro como uma totalidade ou conjunto, adotar a perspectiva do outro, tomar consciência de suas ações constituem um processo de construção gradativa, de autorregulação, de autonomia do pensamento. A autonomia de pensamento e a condição de autorregulação estão implicadas na tomada da perspectiva do outro como referência na resolução de conflitos (Oliveira, 2005).

Nesse contexto, os conceitos de egocentrismo e reciprocidade são apresentados como polos de um mesmo continuum de desenvolvimento (Piaget 1965/1973, 1932/1994). Consideramos importante elucidá-los aqui porque, ao tratarmos do jogo, essas relações se encontram implícitas em alguns momentos e explícitas em outros. O jogo, por sua heurística, cria um contexto favorável à manifestação do egocentrismo ao mesmo tempo em que convida a descentrar. $\mathrm{Na}$ teoria de Piaget, o jogo tem lugar como desencadeador de conflitos tanto cognitivos como sociais no processo de interação com o outro. Os aspectos sociais envolvidos na situação de jogo indicam que a interação provocada pelo jogo convida os jogadores a lidarem com as regras, o que favorece a cooperação, as trocas interindividuais e dá movimento à articulação existente entre aspectos cognitivos e sociais. Em alusão ao ambiente de jogo, Macedo (2009) comenta:

O jogo no contexto de uma partida é um exercício de compreender, de fazer coordenações inferenciais, de tomar consciência de procedimentos, de construir estratégias, de formular um conhecimento sobre o próprio jogo e 
as formulações ou explicações que autorizam ou dão significação às jogadas (p. 50).

Esse conjunto de coordenações, entre peças e tabuleiro, entre ações de todos os jogadores, entre o pensamento e as antecipações das jogadas suas e do outro, entre as emoções explicitadas pelos parceiros do jogo, evidenciará em que medida o pensamento e as ações do sujeito encontram-se permeadas pelo egocentrismo e pela cooperação. Egocentrismo no aporte teórico que subsidia nosso trabalho é compreendido como a indiferenciação de perspectivas ou confusão do ponto de vista próprio com o de outras pessoas, ou da ação das coisas e das pessoas com a própria atividade (Piaget, 1965/1973, 1932/1994).

O papel da descentração no processo de desenvolvimento foi estudado como condição progressiva de tomada de consciência das ações situando sua perspectiva num conjunto de outros possíveis pontos de vista, no qual não há mais o predomínio ou privilégio da própria perspectiva, mas a aceitação de que ela figura como uma dentre as demais. A descentração está diretamente relacionada aos mecanismos de autorregulação em busca de estados de equilíbrio em que um erro pode ser inversamente anulado pelo erro inverso, o que atende à necessidade de transformação do que é definido como coordenação egocêntrica para uma coordenação descentrada (Montangero \& Maurice-Naville, 1998; Piaget, 1965/1973, 1923/1976, 1946/1978, 1947/1983).

É interessante observarmos que a impossibilidade de descentrar o pensamento é um limitador à evolução do mesmo. O desenvolvimento orienta-se justamente na direção do rompimento com as falsas certezas próprias às centrações prévias, o que implica deslocar seu centro, comparar as próprias ações entre si com as ações das demais pessoas. Justamente por depender de sucessivas descentrações e coordenações é que o desenvolvimento atinge a reversibilidade. Essas coordenações são paralelamente individuais e sociais, pois engendram estruturas mentais e mecanismos internos de construção ao mesmo tempo em que implicam em reciprocidade interindividual, própria à cooperação.

A cooperação está diretamente relacionada à capacidade de descentrar, o que permite ao indivíduo o ajuste de seu pensamento ou ação à ação e pensamento dos outros, a partir de relações recíprocas entre os indivíduos que cooperam. É definida como sendo toda e qualquer relação existente a partir de um par, sem que nessa relação interfira qualquer elemento de autoridade de um sobre o outro ou posição de prestígio de um ou mais envolvidos (Piaget, 1932/1994).

\section{Método}

O estudo é de configuração qualitativa, na modalidade de estudo descritivo. De acordo com Gil (2008), nesse tipo de pesquisa, os dados são recolhidos sem a preocupação com a quantificação, e sua análise deve respeitar a forma em que foram registrados. O presente estudo investiga uma situação em que estão envolvidos alunos do Ensino
Fundamental de uma escola estadual em Londrina - PR que frequentam um programa oficial do governo estadual denominado Sala de Apoio à Aprendizagem. O referido programa é destinado ao atendimento de alunos do $6^{\circ}$ ano do ensino fundamental que possuem dificuldades de aprendizagem nas disciplinas de Língua Portuguesa e de Matemática, logo, são aqueles alunos que, na avaliação de seus professores, não acompanham satisfatoriamente o processo de aprendizagem e, por essa razão, são encaminhados à sala de apoio. Participaram da pesquisa 8 alunos do $6^{\circ}$ ano que, no momento da coleta de dados, apresentavam idades que variavam entre 10 anos e 10 meses e 12 anos e 10 meses e eram frequentadores da sala de apoio à aprendizagem.

\section{Instrumentos}

\section{Jogo de Regras Rummikub}

O Jogo é composto por dois conjuntos formados por peças numeradas de 1 a 13, em quatro cores diferentes (azul, laranja, vermelho e preto). Existem ainda dois curingas, representados por duas "carinhas", que exercem a função de substituição da peça faltosa à formação da série, conforme ilustra a figura a seguir.

Figura1. Conjunto de peças do Rummikub.

\begin{tabular}{|l|l|l|l|l|l|l|l|l|l|l|l|l|}
\hline 1 & 2 & 3 & 4 & 5 & 6 & 7 & 8 & 9 & 10 & 11 & 12 & 13 \\
\hline 1 & 2 & 3 & 4 & 5 & 6 & 7 & 8 & 9 & 10 & 11 & 12 & 13 \\
\hline 1 & 2 & 3 & 4 & 5 & 6 & 7 & 8 & 9 & 10 & 11 & 12 & 13 \\
\hline 1 & 2 & 3 & 4 & 5 & 6 & 7 & 8 & 9 & 10 & 11 & 12 & 13 \\
\hline & & & & & $\odot$ & & & & & $-;$ & & \\
\hline 1 & 2 & 3 & 4 & 5 & 6 & 7 & 8 & 9 & 10 & 11 & 12 & 13 \\
\hline 1 & 2 & 3 & 4 & 5 & 6 & 7 & 8 & 9 & 10 & 11 & 12 & 13 \\
\hline 1 & 2 & 3 & 4 & 5 & 6 & 7 & 8 & 9 & 10 & 11 & 12 & 13 \\
\hline 1 & 2 & 3 & 4 & 5 & 6 & 7 & 8 & 9 & 10 & 11 & 12 & 13 \\
\hline
\end{tabular}

Fonte: As autoras.

O objetivo do jogo é esvaziar o tabuleiro descartando todas as peças. Nesse momento, o jogador que esvazia seu tabuleiro deve dizer "Rummikub". Caso se esqueça de dizer e outro diga em seu lugar, perde o direito à batida. Cada jogador inicia com 14 peças escolhidas sem que se possa vê-las. Devem organizar previamente em seus tabuleiros séries por três tipos de agrupamento: três peças de mesmo número e de cores diferentes, ex. 333 (sendo um preto, outro azul, outro laranja); quatro peças se uma das cores for repetida; ou ainda no mínimo três peças sendo que são sequências de números, mantendo-se a cor, ex.456 (todos vermelhos). As peças, após serem baixadas na mesa, podem ser apropriadas por qualquer um dos jogadores para constituir novas jogadas como rearranjos entre as séries. 
O registro dos dados do jogo foi feito por meio de filmagem e relato em protocolo construído pelas pesquisadoras, que simulava no papel os tabuleiros dos jogadores, bem como a movimentação de suas peças ao longo do jogo. A análise dos dados adotou os critérios de tomada de perspectiva (Piaget, 1996).

\section{Apresentação e discussão dos resultados}

Primeiramente apresentamos um quadro geral que organiza o movimento dos jogadores nas 6 sessões avaliativas quanto à condição de negociação da perspectiva do outro. Nesse quadro, apontamos o predomínio das condutas quanto ao egocentrismo e à cooperação na relação interpares mediada pelo jogo. São dados oriundos das observações registradas nos protocolos de observação.

Em um segundo momento, exemplificamos os tipos de condutas lúdicas com fragmentos de jogadores retirados das situações de interação lúdica.

Os dados indicaram que predominantemente os alunos apresentam maior dificuldade que assertividade quando se trata da condição de enfrentamento diante de um desafio. Esta capacidade é importante, pois favorece a independência e autonomia de ações. No referencial teórico que adotamos, a ausência dessa capacidade é lida como resultante da dificuldade de descentrar, de assumir outros pontos de vista e da necessidade egocêntrica no enfrentamento do conflito (Piaget, 1932/1994). É interessante observar que, embora haja dificuldade de enfrentamento diante do desafio, frequentemente ou em boa parte das vezes buscam ativamente a aproximação dos colegas. Isso confirma a relação que fazemos com o egocentrismo do pensamento, pois nos parece garantida a necessidade de troca, o prazer que a companhia do outro possibilita, a condição de interagir, de pertencer ao grupo, entretanto, quando é desse outro que advém o desafio, nem sempre se lida bem com isso, pois ainda prevalece o egocentrismo do pensamento (Piaget, 1926, 1928, 1937/1975, 1946/1978).

Dos oito alunos que constituem a amostra de nosso estudo, seis manifestam oscilação entre o reconhecimento da perspectiva do outro e a centração na perspectiva própria. Esse dado indica um processo gradativo de reconhecimento do outro como parte constituinte de si mesmo e a tomada de uma perspectiva distinta da sua em processo.

A condição de adotar a perspectiva do outro é constituinte da cooperação que, nesse referencial, significa co(operar) ou operar junto, conjuntamente, e operar junto com o outro implica necessariamente que não prevalecerá à opinião de um ou de outro, mas será preciso ajustamento e troca. É compreensível que os participantes, em sua maioria, manifestem diferenças em cooperar, pois a cooperação é fruto de reciprocidade construída nas relações de troca desde uma dupla e se amplia para todas as formas de relação interpessoal. Em todos esses desafios, convida-se o sujeito a descentrar de seu ponto de vista e adotar novas formas de pensamento (Piaget, 1946/1978, 1932/1994). Para o autor, "descentrar-se, ou seja, deslocar seu centro e comparar uma ação com outras possíveis, particularmente com as ações de outras pessoas, conduz a uma consciência do 'como' às verdadeiras operações" (Piaget, 1946/1978, p. 135).

A cooperação relaciona-se à descentração e permite o ajuste do pensamento e da ação dos indivíduos que cooperam entre si, considerando a horizontalidade da relação

Quadro 1. Aspectos relativos à tomada da perspectiva do outro.

\begin{tabular}{|c|c|c|c|}
\hline Categoria & $\begin{array}{c}\text { Enfrentamento dos } \\
\text { desafios do jogo }\end{array}$ & $\begin{array}{c}\text { Tentativa de se } \\
\text { aproximar do } \\
\text { parceiro }\end{array}$ & $\begin{array}{c}\text { Reconhecimento } \\
\text { da perspectiva do } \\
\text { outro }\end{array}$ \\
\hline Classificação & 3 & 5 & \\
\hline Frequentemente & 5 & 3 & 1 \\
\hline Raramente & & & 6 \\
\hline Nunca & & & \\
\hline $\begin{array}{c}\text { Egocentrismo alternando-se com } \\
\text { descentração }\end{array}$ & & & \\
\hline $\begin{array}{c}\text { Condutas descentradas ou } \\
\text { cooperativas }\end{array}$ & & & \\
\hline
\end{tabular}

Fonte: As autoras. 
interpares. Essa relação pode ser um espaço para a construção do respeito mútuo discutido por Piaget (1932/1994).

Apresentamos a seguir alguns fragmentos de protocolos nos quais os procedimentos e estratégias dos jogadores estão registrados.

\section{Predomínio da centração e egocentrismo nas jogadas e nas interações interpares}

Ao observar os dados a seguir, é possível identificar que as perspectivas do outro são percebidas de forma simplista, sem articulação entre elas e o conflito cognitivo que advém tanto do jogo em si, com seus desafios, quanto da intervenção do parceiro. Nesse caso, a perspectiva é unilateral, desarticulada das ações que produziram o impasse e revelam o predomínio do egocentrismo de pensamento (Piaget, 1946/1978) Analisemos o protocolo a seguir:

\section{Fragmento 1}

$\mathrm{Na}$ primeira jogada da $1^{\mathrm{a}}$ sessão avaliativa, A1 ainda não coordena as regras e critérios do jogo e abaixa uma sequência de números diferentes com cores diferentes 789 (sendo o 7 azul, o oito preto e o nove vermelho), sequência que seria possível desde que as peças fossem de cores iguais. Apenas retirou a sequência da mesa quando foi avisado pela pesquisadora, pois o jogador A2 também não observou. Nessa jogada, não houve consideração da cor, apenas da sucessão na sequência.

Na mesma partida, A1 baixou 9876 (todos de cor vermelha, o que atende à regra, em ordem decrescente). Nesse momento, o jogador A2 contestou a jogada do parceiro avisando que deveria ser 678 , então A1 modifica a ordem dos números na mesa. A1 baixou também um grupo com o curinga $44 \div$ (sendo 4 vermelho, 4 preto e curinga vermelho). A figura a seguir representa o que acabamos de comentar

(O símbolo (:) significa o uso do coringa).

Figura 2. Partida representativa entre A1 e A2.

\begin{tabular}{|c|c|c|c|c|c|}
\hline $\mathrm{N}^{\circ}$ da jogada & $\begin{array}{c}\text { Organização do } \\
\text { tabuleiro (A1) }\end{array}$ & Jogada & \multicolumn{3}{|c|}{ Mesa } \\
\hline & $\begin{array}{c}44 @ 11561 \\
2987789\end{array}$ & $\begin{array}{c}\text { dc: } 789 \\
44 @\end{array}$ & 44@ & 9876 & 789 \\
\hline 1 & & & & & \\
\hline
\end{tabular}

Fonte: As autoras.

Obs: Utilizam-se as siglas CP- para compra e DCdescarte.

Os dados apresentados demonstram a dificuldade de coordenação dos observáveis do jogo. Predomina a centração em um ponto de vista ou possibilidade no tabuleiro enquanto as demais são ignoradas, o que limita o jogo do ponto de vista cognitivo. O egocentrismo e a centração evidentes na conduta descrita pelo sujeito A1 em sua jogada são análogos à impossibilidade de coordenar pontos de vista, representada na intervenção que $A 2$ faz no jogo do parceiro. A ausência da condição de perceber que 9876 e 6789 são modos diferentes de arranjar a mesma sequência (ordem crescente ou decrescente) demonstra a centração egocêntrica e localiza os sujeitos A1 e A2 no nível 1 da coordenação da perspectiva nesse momento de jogo. Tanto o é que A1 não questiona o parceiro quando este pede a inversão da ordem decrescente para crescente na sequência realizada. Ele acata sem coordenar essa nova informação à anterior e sem perceber que isso não acarreta qualquer mudança efetiva no jogo.

Acatar o desenvolvimento da cooperação como processo implica no entendimento de que as ações dos jogadores, as peças envolvidas no tabuleiro, os planejamentos de jogadas, as estratégias de ações antecipadas, a condição de observar o jogo do outro e tomá-lo como referência ao seu próprio jogo são construções gradativas e codependentes. Em especial nas obras $A$ formação do símbolo na criança (1978) e O juízo moral na criança (1994), Piaget se dedicou a analisar justamente esses processos de gradativo crescimento, tomando situações de interação lúdica entre as crianças por base. Acentua o autor (Piaget, 1932/1994) que o egocentrismo do pensamento vai gradativamente cedendo lugar às formas mais descentradas de pensamento em direção à cooperação.

\section{Evolução na construção da perspectiva na relação interpares}

Para exemplificar a evolução qualitativa, elegemos o jogo de A2 na terceira sessão avaliativa. A mesma falta de coordenação pode ser observada em outra jogada na qual $A 2$, tendo várias possibilidades, não as coordena, e a centração em uma única perspectiva impede descartes mais significativos para atingir o propósito do jogo. Coordenar ações em pensamento implica na tomada da consciência das ações e na construção de jogo de conjunto. Coordenar parte e todo em um jogo é tarefa complexa e requer sucessivas regulações (Piaget, 1980).

\section{Fragmento 2}

$\mathrm{Na}$ jogada 22 da terceira sessão avaliativa, A2 está com o 12 e 13 (pretos) e não vê a possibilidade de colocá-los na sequência 91011 (pretos), isso revela a ausência de articulação das peças do tabuleiro com a mesa. No entanto, abaixa o 8 (preto) que havia comprado na jogada 20. Ele se preocupa em articular a peça que comprou e não a que já possui no tabuleiro, ou seja, demonstra o egocentrismo por não ver a perspectiva na mesa de aumentar a sequência 8 91011 (sendo todos pretos) com o 12 e 13 (ambos pretos) que possui. Porém, na mesma jogada, articula a peça 
11(preto) da sequência e coloca no grupo 111111 (sendo 11 preto, 11 azul e 11 vermelho). Percebemos que o jogador, nessa situação, não considera a relação com o todo, ou seja, tabuleiro, mesa, compra, descarte. Nessa jogada, A2 ainda teria a possibilidade de deslocar do grupo $111111 \underline{11}$ (sendo 11 preto, 11 azul, 11 vermelho, 11 preto) o 11 para a sequência $910 @$, colocando o 11 no lugar no curinga e podendo baixar do tabuleiro o 13.

Figura 3. Partida representativa entre A1 e A2.

\begin{tabular}{|c|c|c|c|}
\hline $\begin{array}{l}\mathrm{N}^{\circ} \text { da } \\
\text { jogada }\end{array}$ & $\begin{array}{l}\text { Organizaçäo do } \\
\text { tabuleiro (A2) }\end{array}$ & Jogada & Mesa \\
\hline Fonte? ${ }^{2} \mathrm{As}$ & $\begin{array}{l}\begin{array}{l}3213113 \quad 6 \\
8128 \\
\text { toras. }\end{array}\end{array}$ & Dc: 8 & $\begin{array}{l}9998991011910 @ \\
12345444111111111 \\
8910\end{array}$ \\
\hline
\end{tabular}

Observar os sujeitos em situação de jogo é interessante, pois revela que, em um mesmo jogo, é possível que as jogadas e estratégias empregadas pelos parceiros sejam diferenciadas em sua qualidade. Embora ainda não coordene todas as possibilidades de jogo, A2 elabora corretamente as sequências, ao contrário de A1 (ver figura 2), não coordena as regras e considera a sequência, mas ignora as cores nesta montagem. Registramos essa observação para ratificar as discussões teóricas já anunciadas a respeito da evolução contínua nos procedimentos e na estrutura de pensamento dos sujeitos em situação de desafio social e cognitivo, como aqueles que o jogo engendra (Macedo, 2009; Oliveira, 2005).

A construção da perspectiva interpares é caracterizada por maior coordenação do jogo, de suas possibilidades, das articulações entre jogadores e seus jogos e os jogos do outro, o pensamento do outro aplicado ao seu jogo e a dinâmica resultante dessas coordenações. Coordenar tantos possíveis não é uma tarefa fácil (Piaget, 1986). Isso indica articulação de diferentes pontos de vista, distintos observáveis, portanto níveis mais aprimorados de tomada da perspectiva do outro. As coordenações é que permitem ao jogador considerar que o deslocamento só deve ser utilizado se for para auxiliar na jogada e não apenas para modificar os arranjos espaciais na mesa sem nenhum fim imediato que resulte em pelo menos uma peça eliminada de seu tabuleiro. Analisemos este fragmento apresentado.

Fragmento 3

A7, na jogada 30 da $4^{\mathrm{a}}$ sessão, abaixou 2 e 4 (vermelho) do tabuleiro e fez um deslocamento da peça $\mathbf{3}$ (vermelho) da mesa para completar a sequência. Nessa jogada, A7 teria mais uma possibilidade, que seria a de retirar o 10 (azul) da sequência 10111213 (azuis), colocar no grupo 1010 10, retirar o 10 (preto) e o 9 (preto) do grupo 99999 9, descer do tabuleiro o 11 e formar 910 11, aproveitando melhor a jogada. Constatamos a dificuldade de A7 em descentrar as suas ações. Na mesa, tinha uma sequência de 777 ,
A7 pegou o 7 (vermelho) e colocou na sequência 78910 (vermelho). Seu parceiro, A8, deu risada e disse que ele não fez nada. A7 disse para A8: "só para fazer alguma coisa", ou seja, também reconhece que sua ação sobre a mesa não acrescenta nada novo nem para a mesa, nem para sua forma de jogo.

Figura 4. Partida representativa entre $\mathrm{A} 3, \mathrm{~A} 4, \mathrm{~A} 5$ e $\mathrm{A} 7$.

\begin{tabular}{|c|c|c|c|}
\hline $\begin{array}{l}\mathrm{N}^{\circ} \text { da } \\
\text { jogada }\end{array}$ & $\begin{array}{c}\text { Organização do } \\
\text { tabuleiro (A7) }\end{array}$ & Jogada & Mesa \\
\hline 30 & 42111213156 & Dc: 24 & $\begin{array}{l}12 J 345 \quad \underline{3} 33 \quad \underline{234} \\
7777 \quad 222 \quad 345 \\
999999 \quad \underline{7} 8910 \\
101010 \quad 345678 \quad 10111213\end{array}$ \\
\hline
\end{tabular}

O protocolo de outra dupla, apresentado a seguir, revela a presença de coordenação do tabuleiro com a mesa alternando-se com o egocentrismo predominante nas condutas. É interessante observar, nas jogadas, que justamente por ser processo, coexistem ações egocêntricas e coordenações.

Fragmento 4

Na jogada 50 da quarta sessão, no momento de A3 jogar, A4 interfere e pergunta a A3: "Você tem algum dois de qualquer cor?"; A3 desceu apenas a peça 2 (laranja) na mesa e colocou no grupo 222 (azul, preto, preto), ficando 2222 (azul, preto, preto e laranja). A3 tinha várias outras possibilidades de descer peças e fazer rearranjos. As novas perspectivas postas na mesa em função das jogadas dos colegas não são percebidas pelos jogadores. A4, centrado na sua única possibilidade, estava inferindo e antecipando a possibilidade de que se o jogador que jogasse antes dele colocasse um 2 de qualquer cor no grupo 222 (sendo preto, preto, azul), ele iria ganhar o jogo, pois com mais uma peça 2 no grupo ele poderia pegar o 2 (azul) 2222 (preto, preto, azul e laranja) e a peça de seu tabuleiro que era o 1 (azul) e deslocar o 1 e 2 para a sequência 345 da mesa, como mostra o protocolo da jogada 52.

Figura 5. Partida representativa entre A3, A4, A5 e A7.

\begin{tabular}{|c|c|c|c|}
\hline $\begin{array}{l}\mathrm{N}^{\circ} \mathrm{da} \\
\text { jogada }\end{array}$ & $\begin{array}{l}\text { Organização } \\
\text { do tabuleiro } \\
\text { (A4) }\end{array}$ & Jogada & Mesa \\
\hline Fonte: As & utoras. & Dc: 1 & $\begin{array}{l}6781 \mathrm{~J} 2345222 \underline{2} 111213 \\
7777777 \text { 1 } 2345910111212 \mathrm{~J} 12 \\
3332349999789106661010103456 \\
789\end{array}$ \\
\hline
\end{tabular}

Constatamos que A4, por meio da inferência e antecipação, mostrou coordenar essa jogada, fazendo um 
deslocamento da peça necessária para atingir o objetivo do jogo e ganhar a partida. Como em seu tabuleiro estava com a peça 1 e a mesa apresentava o jogo $\mathbf{3} 45$ e um grupo $\underline{2} 2$ 2 2, pois o último 2 tinha sido colocado na jogada anterior, por antecipação, ao questionar sobre a peça que estava esperando, revela seu pensamento, que indicava a percepção da possibilidade de colocar o 2 na sequência 345 , ficando 2 34 5, e descartar a última peça 1, vencendo o jogo.

Esse fragmento se caracteriza pela possibilidade de coordenar diferentes pontos de vista e integrá-los nas escoIhas que faz. Implica em jogo de conjunto, no qual todas as peças são consideradas possibilidades e são articuladas na tomada de decisão ou elaboração da estratégia a ser empregada (Piaget, 1980).

É interessante percebermos que, em uma mesma jogada, podem se evidenciar estruturas de jogo diferenciadas. Essa é a riqueza da interação interpares. O jogo de um dos parceiros pode ser mais elaborado e isso suscitar mudança no jogo do outro. A construção de estratégias mais elaboradas pode ser desencadeada, e o pensamento, aprimorado. O protocolo que apresentamos a seguir revela um jogo mais elaborado no caso de A8.

\section{Fragmento 5}

No protocolo abaixo, A8 definiu o jogo na $5^{\mathrm{a}}$ sessão, fazendo coordenações na mesa e eliminando suas peças do tabuleiro. Esse protocolo permite constatar a presença de coordenação do tabuleiro com a mesa, assim como a descentração e o observável para as perspectivas postas na mesa em função das jogadas dos colegas. A8 descarta o 6 (laranja) na sequência $\mathbf{3} \mathbf{5}$ (sendo todos da cor laranja). Agrupou as duas sequências de número 12, ficando $\underline{12}$ $1212-1212$ (sendo das cores laranja, vermelho, preto, curinga, laranja, preto), retirou o 12 (laranja) e o 11 (laranja) da sequencia $1111 \underline{11} 11$ (sendo preto, azul, laranja, preto) e descartou o 10 (laranja) do seu tabuleiro, formando 1011 12 (todos laranjas). Nesse momento, estava apenas com a peça 2 (azul) e, para alocá-la na mesa, retirou o 3 (laranja) da sequencia 3456 (todos laranjas), deslocou para o grupo $3 \underline{3} \mathbf{3}$ (sendo vermelho, azul, vermelho) e retirou o $\mathbf{3}$ (azul). Retirou o 4 (preto) da sequencia $123 \underline{4}$ () (todos pretos e curinga vermelho) e deslocou para o grupo 444 (sendo preto, vermelho e azul), ficando 4444 (preto, vermelho, azul, preto), sendo assim pôde retirar o 4 (azul) e formar 23 4 (todos azuis) e ganhar a partida.

Lembrando que a regra do jogo não permite abaixar 3 peças de números iguais com uma cor repetida, mas, no rearranjo das jogadas, a regra permite deixar a cor repetida.

Figura 6. Partida representativa entre A6 e A8.

\begin{tabular}{|c|c|c|c|}
\hline $\begin{array}{l}\mathrm{N}^{\circ} \text { da } \\
\text { jogada }\end{array}$ & $\begin{array}{l}\text { Organização } \\
\text { do tabuleiro } \\
\text { (A8) }\end{array}$ & Jogada & Mesa \\
\hline Fonte: As a & oras. & Dc: 6 & $\begin{array}{l}9999123 \underline{J} \mathrm{~J} 3 \underline{3} 3 \underline{3} \\
121212 \mathrm{~J} \underline{1212} 567 \\
44411117898910 \\
1111 \underline{1111} 101112234 \\
10111213 \underline{34} 5 \underline{6} 666\end{array}$ \\
\hline
\end{tabular}

As relações articuladas organizadas por um planejamento prévio indicam as características da tomada de perspectiva do outro.

\section{Conflito sociocognitivo e contestação do pensamento - o papel do outro}

O fragmento que apresentamos a seguir evidenciou de modo peculiar o lugar do jogo na perspectiva piagetiana como um desencadeador de situações de desafio cognitivo por meio do conflito. Diante dos conflitos sociocognitivos, o jogador é convidado a construir novas estratégias, elaborar novos planejamentos para suas ações, o que implica em regulações e reorganizações contínuas e progressivas (Macedo, 2009). Observemos as jogadas descritas no fragmento 6.

$\mathrm{Na}$ jogada 38 da quarta sessão, no momento de A7 jogar, a mesa apresentava a sequência 3456789 de peças vermelhas, A5 apenas separou a sequência em duas (3 45 6 e 78 9) e disse ao parceiro: "pode passar", indicando que já havia jogado. O jogador A5 já conhecia as regras, pois além das 3 sessões de aprendizagem, esse lance aconteceu na quarta sessão avaliativa, portanto no $7^{\circ}$ dia de contato do jogador com o jogo. Como A7 não queria adquirir mais uma peça para o seu tabuleiro e não viu a possibilidade de descarte das peças que tinha em mãos, tentou burlar a regra. Nesse protocolo, constatamos que o jogador A7 teria possibilidades de descarte, tais como deslocar o 10 (azul) da sequência 10111213 (sendo todos azuis) para o grupo 1010 10, ficando 101010 10, retirando o 10 (preto), o 9 (preto) do grupo 999999 e baixar o 11 (preto) formando 910 11. Mais uma possibilidade era possível: descartar o 5 (vermelho) na sequência 678 , ou mesmo fazer um novo rearranjo das sequências, 3456 e 78 9, deslocando o 6 para a sequência 789 , ficando 6789 , dando a possibilidade de colocar o 5 , ficando 56789 . No momento em que ele falou para o colega seguir o jogo e diante do fato de que o colega não percebeu a manobra do parceiro, o conflito cognitivo e social foi oferecido pela pesquisadora, que questiona: "você se lembra que, pela regra do jogo, você agora deve comprar uma peça ou descartar uma peça que já tem?". Ele respondeu que havia comprado. O outro jogador pergunta que peça ele comprou e ele responde: "comprei o 9 vermelho" (o que não era verdade). Mas, percebendo que 
não havia como sustentar a afirmação, deu risada e então comprou uma nova peça.

Figura 7. Partida representativa entre $A 3, A 4, A 5$ e $A 7$.

\begin{tabular}{|c|c|c|c|}
\hline $\mathrm{N}^{\circ}$ da jogada & $\begin{array}{c}\text { Organização do } \\
\text { tabuleiro (A7) }\end{array}$ & Jogada & Mesa \\
\hline Fonte: As autor & $\begin{array}{l}11121315 \\
612\end{array}$ & Cp: 5 & $\begin{array}{l}67812 @ 345 \\
7777777222333234 \\
99999978910101010 \\
\frac{3456}{34510} \frac{789}{111213666}\end{array}$ \\
\hline
\end{tabular}

O fragmento apresentado nos permitiu analisar o papel do pesquisador nas possibilidades de intervenção junto aos jogadores, mediando seu jogo, introduzindo novos desafios cognitivos, afetivos e sociais. Os impasses vividos pelos jogadores, as discordâncias entre eles, os desafios do jogo servem de indicativos para a atuação do professor quando faz uso do jogo em sala de aula. Acatamos o posicionamento de que o jogo, por sua estrutura, objetivos e regras, engendra desafios, mas se torna muito mais rico quando situações problematizadoras são introduzidas intencionalmente, planejadamente nas situações de jogo e servem para desencadear a descentração e a tomada da perspectiva do outro (Oliveira, 2005; Piantavini, 1999).

\section{Considerações finais}

O egocentrismo e a descentração na relação interpares evidenciou-se na presente pesquisa, como constituinte da tomada de perspectiva do outro. Desencadeou a compreensão do processo gradativo de afastamento das posições próprias e das certezas oriundas da percepção distorcida do real para formas mais articuladas de pensamento e possibilidades de apropriação de pontos de vista distintos do seu. Foi possível perceber nas condutas dos jogadores do jogo Rummikub que, vivenciando os desafios cognitivos e sociais presentes na estrutura do jogo, o pensamento é convidado à transformação por sucessivas coordenações dos elementos envolvidos no jogo.

A atividade própria à construção do conhecimento implica na necessidade de confrontar o próprio pensamento e isso o jogo de regras possibilita tanto na estrutura que engendra quanto nas possibilidades de trocas sociais que desencadeia. Por essa razão, é possível compreender que, na dimensão social, o sujeito confirma ou contesta seu pensamento, o que constitui a interação social como um dos fatores de desenvolvimento, corresponsável na construção do conhecimento.

Entender o modo como sujeitos em processo de escolarização estabelecem acordo entre seu "mundo interno" e os aspectos desequilibradores dos relacionamentos interpessoais constitui-se importante temática de discussão suscitada para pesquisas futuras. Nosso estudo indicou que, nas trocas interpares, estão presentes coordenações não só relativas ao pensamento, mas que indicam gradativas possibilidades na compreensão dos problemas, emoções vividas e desafios que surgem. É progressivamente que os sujeitos atingem a condição de cooperar, de lidar de forma mais descentrada nas relações interpares.

A indiferenciação própria do egocentrismo imprime um funcionamento típico que se traduz na confusão entre o ponto de vista pessoal e do outro, ou entre as atividades do sujeito e as transformações do objeto e constitui a intersecção entre aspectos cognitivos e sociais nas condutas que analisamos. Essa característica do pensamento está diretamente relacionada à dificuldade de descentração do pensamento. Há, na centração, portanto, a impossibilidade de relativizar, de considerar outras perspectivas, coordenar pontos de vista. A adaptação do indivíduo ao meio social e ao meio físico implica na construção de um conjunto de relações coordenadas entre si por reciprocidade de diferentes pontos de vista, que pode ser construída por meio de situações de jogo.

Como implicação pedagógica, indicamos duas questões: o aprimoramento desse processo de construção da tomada de perspectiva deve ser incentivado nas proposições que fazemos aos alunos no processo de escolarização e a indicação do uso do jogo de regras na escola com o objetivo de favorecer esta construção.

\section{Referências}

Brenelli, R. P. (1996). O jogo como espaço para pensar. A construção de noções lógicas e aritmética. Campinas, SP: Papirus.

Fiorot, M. A., \& Ortega, A. C. (2009). Modos de Aprender e de Ensinar de Professoras em situações com o jogo Traverse. Em L. de Macedo (Org.), Jogos, Psicologia e educação: teoria e pesquisas (pp. 97-124). São Paulo: Casa do Psicólogo.

Garcia, H. H. G. O. (2010). Adolescentes em grupo: aprendendo a cooperar em oficina de jogos. Tese de Doutorado em Psicologia Experimental, Instituto de Psicologia, Universidade de São Paulo, São Paulo..

Gil, A. C. (2008). Como elaborar projetos de pesquisa (4a ed.). São Paulo: Atlas.

Macedo, L. (1994). Ensaios construtivistas (3a ed.). São Paulo: Casa do Psicólogo.

Macedo, L. (Org.). (2009). Jogos, psicologia e educação: teoria e pesquisas. São Paulo: Casa do Psicólogo.

Montangero, J., \& Maurice-Naville, D. (1998). Piaget ou a inteligência em evolução: sinopse cronológica e vocabulário. Porto Alegre: Artmed.

Oliveira, F. O. (2005). Um estudo de interdependências cognitivas e 
sociais em escolares de diferentes idades por meio do jogo Xadrez Simplificado. Tese de Doutorado em Educação, Universidade Estadual de Campinas, Campinas, São Paulo.

Oliveira, F. N., \& Macedo, L. (2011). Resiliência e insucesso escolar: uma reflexão sobre as salas de apoio à aprendizagem. Revista Estudos e Pesquisas em Psicologia, 11(3), 983-1004.

Piaget, J. (1926). A representação do espaço na criança. Porto Alegre: Artes Médicas.

Piaget, J. (1928). Logique génétique et sociologie. Revue philosophique de la France et de l'étranger, 57, 167-205.

Piaget, J. (1969). Sabedoria e ilusões da Filosofia (Z. A. Daeir, Trad.). São Paulo: Difusão Européia. (Obra Original publicada em 1965)

Piaget, J. (1973). Estudos sociológicos. Rio de Janeiro: Forense. (Obra Original publicada em 1965)

Piaget, J. (1975). A construção do real na criança (Á. Cabral, Trad.). Rio de Janeiro: Zahar. (Obra Original publicada em 1937)

Piaget, J. (1976). Linguagem e pensamento na criança. Rio de Janeiro: Zahar. (Obra Original publicada em 1923)

Piaget, J. (1978). A formação do símbolo na criança: imitação, jogo e sonho, imagem e representação (Á. Cabral, Trad.). Rio de Janeiro: Zahar. (Obra Original publicada em 1946)

Piaget, J. (1980). A psicologia da criança. São Paulo/Rio de Janeiro: DIFEL.

Piaget, J. (1982). O nascimento da inteligência na criança. Rio de Janeiro: Zahar.
Piaget, J. (1983). Psicologia da inteligência. Rio de Janeiro: Zahar. (Obra Original publicada em 1947)

Piaget, J. (1986). O possível e o necessário: evolução dos necessários na criança. Porto Alegre: Artes Médicas.

Piaget, J. (1994). O juízo moral na criança (E. Leonardon, Trad.). São Paulo: Summus. (Obra Original publicada em 1932)

Piaget. J. (1996). As formas elementares da dialética (F. M. Luiz, Trad.). São Paulo: Casa do Psicólogo.

Piantavini, F. N. O. (1999). Jogo de regras e construção de possíveis: análise de duas situações de intervenção psicopedagógica. Dissertação de Mestrado em Educação, Curso de Pós-Graduação em Educação, Universidade Estadual de Campinas, Campinas, São Paulo.

Ribeiro, M. P. de O., \& Rossetti, C. B. (2009). Os Jogos de Regras em uma abordagem piagetiana: o estado da arte e as perspectivas futuras. Em L. de Macedo (Org.), Jogos, Psicologia e educação: teoria e pesquisas (pp. 11-33). São Paulo: Casa do Psicólogo.

Tortella, J. C. B. (2001). A representação da amizade em díades de amigos e não amigos. Tese de Doutorado em Educação, Faculdade de Educação da Universidade Estadual de Campinas, Campinas, São Paulo.

Turiel, E., \& Smetana, J. G. (1989). Conocimiento Social y accion: la coordinacion de los domínios. Em E. Turiel, I. Enesco \& J. Linaza, El mundo social en la mente infantil (pp. 389-407). Madrid: Alianza.

\section{Sobre as autoras}

Gisele Bueno de Farias Rebeiro (giselebfr@hotmail.com.br)

Universidade Estadual de Londrina - UEL

Francismara Neves Oliveira (francismara@sercomtel.com.br)

Universidade Estadual de Londrina - UEL

Geiva Carolina Calsa (gccalsa@uem.br)

Universidade Estadual de Maringá - UEM 
